\title{
Human CD133-positive hematopoietic progenitor cells enhance the malignancy of breast cancer cells
}

\author{
Zhe Zhang ${ }^{1}$, Qinglian Zheng ${ }^{1}$, Yonghui Liu', Lianqing Sun ${ }^{1}$, Pingping Han', Rui Wang ${ }^{1}$, Jiao Zhao', Shan Hu and
} Xinhan Zhao ${ }^{2^{*}}$

\begin{abstract}
Background: Human CD133+ hematopoietic progenitor cells (HPCs) are a specific subset of cells that can regulate tumor malignancy. However, the mechanism by which CD133+ HPCs affect the malignancy of human breast cancer has not been reported.

Methods: CD133+ HPCs were isolated and purified from human umbilical cord blood (UCB). We used in vitro culture of MCF-7 and MDA-MB-231 cell lines, and MCF-7 and MDA-MB-231 cells in nude mice to evaluate whether CD133+ HPCs affected the apoptosis, proliferation, invasion and epithelial mesenchymal transition EMT of breast cancer cells.

Results: Co-culture with CD133+ HPCs, but not UCB CD133- cells, promoted the proliferation of human breast cancer MCF-7 and MDA-MB-231 cells, accompanied by reducing in vitro spontaneous apoptosis. Co-administration of these two lines with CD133+ HPCS significantly enhanced the growth of implanted breast cancer in vivo. Furthermore, co-culture with CD133+ HPCs, enhanced the invasion of breast cancer cells, N-cadherin and Vimentin expression, but reduced E-cadherin expression in breast cancer cells.

Conclusions: Our study demonstrated that CD133+ HPCs enhance the malignancy of breast cancer cells by attenuating spontaneous apoptosis and promoting the process of epithelial mesenchymal transition. These findings may provide new insights into the role of human CD133+ HPCs in breast cancer pathogenesis. Therefore, CD133+ HPCs may be a new therapeutic target for inhibiting the progression of breast cancer.
\end{abstract}

Keywords: CD133, Hematopoietic progenitor cells, Breast cancer cells, Malignancy

\section{Background}

Breast cancer metastasis is a significant cause of cancerrelated death in women. Cancer metastasis is a dynamic process and is regulated by many factors. During cancer metastasis, malignant tumor cells are subjected to a series of changes, including alterations in cytoskeleton, morphology,

\footnotetext{
* Correspondence: 2562250493@qq.com

${ }^{2}$ Department of Medical Oncology, the First Affiliated Hospital of Medical School of Xi'an Jiaotong University, Xi'an, Shaanxi 710061, People's Republic of China

Full list of author information is available at the end of the article
}

proliferation and invasion capacities to enhance malignancy. It is notable that malignant tumor cells often undergo epithelial mesenchymal transition (EMT), characterized by loss of epithelial markers (e.g., E-cadherin) and acquisition of mesenchymal $\mathrm{N}$-cadherin and Vimentin expression. However, it is unclear how these factors regulate the EMT process and metastasis in breast cancer [1,2].

The development of metastases is influenced by an intricate interaction between breast cancer cells and the microenvironment [3]. Prior work has shown that cells

(c) The Author(s). 2020 Open Access This article is licensed under a Creative Commons Attribution 4.0 International License, which permits use, sharing, adaptation, distribution and reproduction in any medium or format, as long as you give appropriate credit to the original author(s) and the source, provide a link to the Creative Commons licence, and indicate if changes were made. The images or other third party material in this article are included in the article's Creative Commons licence, unless indicated otherwise in a credit line to the material. If material is not included in the article's Creative Commons licence and your intended use is not permitted by statutory regulation or exceeds the permitted use, you will need to obtain permission directly from the copyright holder. To view a copy of this licence, visit http://creativecommons.org/licenses/by/4.0/. The Creative Commons Public Domain Dedication waiver (http://creativecommons.org/publicdomain/zero/1.0/) applies to the data made available in this article, unless otherwise stated in a credit line to the data. 
existing in the metastatic microenvironment are recruited from bone marrow derived cells [4]. In particular, the bone marrow-derived hematopoietic progenitor cells (HPC) are involved in the initiation of metastases [5]. HPCs are primitive cells predominantly in hematopoietic tissues, such as the bone marrow and umbilical cord blood (UCB) [6-8]. HPCs can proliferate and differentiate into various kinds of blood cells. Human HPCs can be recognized by their surface $\mathrm{CD} 133$ and $\mathrm{CD} 34$ expression [9-13]. The early developing human CD133+ HPCs are a subpopulation of cells in the bone marrow, fetal liver, UCB and peripheral blood [14-18]. Functionally, CD133+ HPCs have stronger proliferation and migration potential than CD133- cells, perhaps, representing more primitive hematopoietic cells $[19,20]$. A recent study suggested that CD133+ human umbilical hematopoietic progenitor cells may induce proliferation or metastasis of colorectal cancer cells [21]. However, few experiments have addressed the role of HPCs in breast cancer. Furthermore, clinical studies indicate that transplantation with hematopoietic stem cells after high dose of chemotherapies benefits patients with advanced breast cancer [22, 23]. However, there is little information on how human HPCs regulate the malignancy of breast cancer.

UCB can be obtained easily and is an excellent alternative source of HPCs. In this study, we isolated human CD133+ HPCs and CD133- cells from human UCB and tested whether CD133+ HPCs modulated the malignancy of breast cancer cells in vitro and in vivo to explore the potential mechanisms involved in metastasis.

\section{Methods}

\section{Isolation of CD133+ HPCs}

The Human Ethics Committee of the First Affiliated Hospital, College of Medicine at Xi'an Jiaotong University approved the experimental protocol (2017-041). Written informed consent was signed the parents of individual newborns. Fresh and healthy human UCB samples (about 60-100 ml) were collected from five human newborns in our hospital. The CD133+ HPCs were isolated by immunomagnetic beads and Magnetic Activated Cell Sorting (MACS) column (Mitenyi Biotec, Germany) according to the manufacturer's instructions. Briefly, the mononuclear cells in the UCB samples were isolated by density gradient centrifugation at $2000 \mathrm{rpm}$ for 25 mins using human lymphocyte separation solution. After being washed, the collected mononuclear cells $\left(1 \times 10^{8}\right.$ cells/sample $)$ in $5 \mu \mathrm{g} /$ $\mathrm{ml}$ BSA (Merck, Germany) and $2 \mathrm{mmol} / \mathrm{ml}$ EDTA buffer (Promega, USA) were blocked with anti-CD16/anti-CD32 (Promega, USA) and stained with anti-human CD133 immunomagnetic beads, followed by loading into the Macs column. During column washing, the flow-through CD133- cells were collected and the bound CD133+ HPCs were eluted. The CD133+ and CD133- cells were stained with PE-anti-CD133 (MBS851590, MyBioSource, California, USA) and FITC-anti-CD34 (MBS850595, MyBioSource, California, USA). The percentages of CD133 + CD34+ cells were analyzed by flow cytometry, the remaining cells were designated CD133- human umbilical cord blood cells (HUCBCs). The isolated CD133+CD34+ HPCs were routinecultured in IMDM (Novagen, USA) medium containing 10\% of fetal bovine serum (FBS, MyBioSource), and semi suspended in a $37^{\circ} \mathrm{C} / 5 \% \mathrm{CO}_{2}$ incubator. Cell growth was monitored daily.

\section{Culture of breast cancer cells}

MCF-7 and MDA-MB-231 breast cancer cell lines were purchased from Shanghai cell bank of the Chinese Academy of Sciences. The cells were cultured with DMEM (MCLAB, USA) containing 10\% newborn bovine serum (MCLAB, USA) under the conditions of $37^{\circ} \mathrm{C}$ and $5 \% \mathrm{CO}_{2} .0 .25 \%$ trypsin (MCLAB, USA) was used to digest and passage. Fresh medium was replaced every $2-3$ days.

\section{Cell proliferation assay}

The effect of CD133+ HPCs on the proliferation of breast cancer cells was quantified by 3-(4,5-dimethylthiazol-2-yl)-2,5-diphenyltetrazolium bromide (MTT) assays [24]. MCF-7 and MDA-MB-231 breast cancer cells in logarithmic growth period were inoculated in 96 well plates, $2 \times 10^{3}$ breast cancer cells for each group. After $12 \mathrm{~h}$ of culture, CD133+ HPCs and CD133HPCs were added to the experimental group and the negative control group in a 20:1 proportion of breast cancer cells to HPCs. 24 h later, each well was dosed with $200 \mu \mathrm{L}$ serum-free medium DMEM and $20 \mu \mathrm{l} 5$ $\mathrm{mg} / \mathrm{ml}$ MTT (MCLAB, USA). After $4 \mathrm{~h}, 150 \mu \mathrm{L}$ of DMSO (MCLAB, USA) was added to each well and incubated at room temperature for $10 \mathrm{~min}$, oscillated with a micro-oscillator for $15 \mathrm{~min}$, and optical density value was recorded at $570 \mathrm{~nm}$ with a flow cytometer instrument. All measurements were performed in triplicate.

\section{Transwell invasion assay}

We examined the influence of CD133+ HPCs on breast cancer cell invasion by Transwell invasion assay [25]. Briefly, the upper and lower chambers of a Transwell insert are separated by polycarbonate microporous membrane ( $8 \mu \mathrm{m}$ pore size), which is coated with Matrigel (Thermo Scientific, USA) on the upper chamber surface and dried at room temperature. $1 \times 10^{5}$ breast cancer cells were added to the upper chamber. CD133+ HPCs and CD133- HPCs were added to the lower chamber of the experimental group and the negative control group. The cell number ratio of breast cancer cells to HPCs was 20:1. After 
culturing at $37^{\circ} \mathrm{C}$ for $24 \mathrm{~h}$, the non-invasive cells were wiped off with a cotton swab. The filter membrane was fixed with $4 \%$ paraformaldehyde solution (Thermo Scientific, USA) for $30 \mathrm{~min}$, and $0.01 \%$ crystal violet dye solution was added for a 20 min incubation. The migrating cells were photoimaged and counted under the microscope. All measurements were performed in triplicate, and the experiments were repeated three times independently.

\section{Cell apoptosis assay}

We tested the role of CD133+ HPCs in spontaneous apoptosis of MCF-7 or MDA-MB-231 cells by flow cytometry [26]. The cancer cells were cultured alone (blank control), or together with CD133+ HPCs or CD133- HUCBCs at a proportion of 20:1 in the upper and lower chambers of the Transwell insert $(0.4 \mu \mathrm{m}$ pore size), respectively, for $72 \mathrm{~h}$. The cancer cells $\left(3 \times 10^{5}\right.$ cells/tube) were tested for apoptosis by flow cytometry after staining with $5 \mu \mathrm{L}$ Annexin V-FITC (Promega, USA) and $10 \mu \mathrm{L}$ Propidium iodide (PI, MyBioSource). The apoptotic FITC+ and FITC+PI+ cells were quantified and the experiment was repeated three times.

\section{Western blotting}

The Transwell $(0.4 \mu \mathrm{m})$ indirect co-culture method and groups were described as above. The MCF-7 and MDAMB-231 breast cancer cells were digested with $0.25 \%$ trypsin, and $250 \mu \mathrm{L}$ RIPA lysate was added, incubated on ice for $10 \mathrm{~min}$, and centrifuged at $4{ }^{\circ} \mathrm{C}$ for $20 \mathrm{~min}$. Following centrifugation, the supernatant was collected and the protein concentration of each group of samples was detected on the spectrophotometer. A 10\% separation gel and $5 \%$ concentrated gel were prepared, a $20 \mu$ g protein was mixed with $2 \times$ SDS sample buffer in a 1:1 ratio. Samples were added to the gel followed by electrophoresis (concentrating gel $80 \mathrm{~V}$; separating gel $100 \mathrm{~V})$. The gel interlayer was removed and the target protein and $\beta$-actin were isolated according to molecular weight. The proteins were transferred to a PVDF membrane followed by soaking the membrane in methanol. The membrane was placed in 5\% skimmed milk powder prepared by TBST for non-specific antigen blocking, and then Rabbit anti rat E-cadherin antibody (Merck, Germany, diluted in 1:2000), Rabbit anti rat Vimentin (Merck, Germany, diluted in1:500), Rabbit anti rat N-cadherin antibody (Merck, Germany, diluted in 1:500), or Rabbit anti rat $\beta$-actin antibodies were added (Merck, Germany, diluted in 1:2000). The membrane was washed three times with TBST, then Sheep anti rabbit IgG (Merck, Germany, diluted in 1: 5000) labeled by HRP (Merck, Germany) was added for incubation followed by $3 \mathrm{x}$ TBST wash. After the film dried slightly, it was incubated with supersignal chemiluminescent reagent (Merck, Germany). The membrane was placed in a dark box and exposed together with the X-ray film (Merck, Germany). The exposure time was about $1 \mathrm{~min}$. X-light was photographed after developing and fixing, and the gray value of the strip was analyzed by gel image analysis software IMAGE-J.All measurements were performed in triplicate, and the experiments were repeated three times independently. a

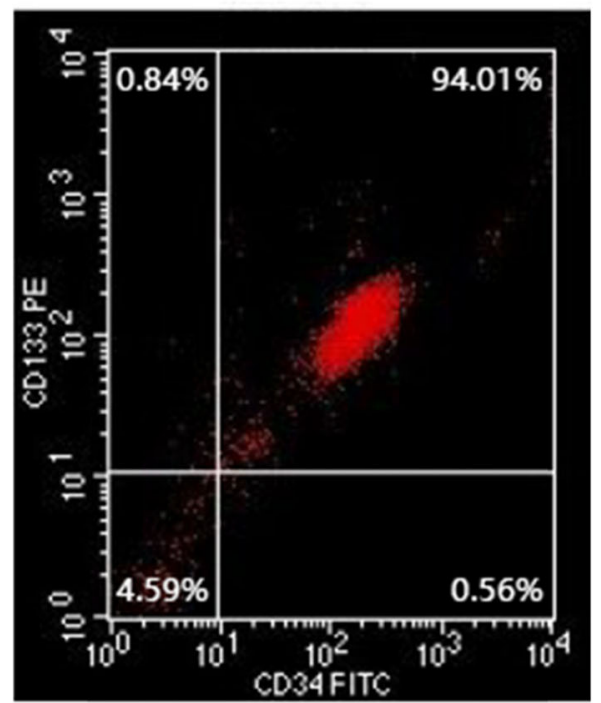

b

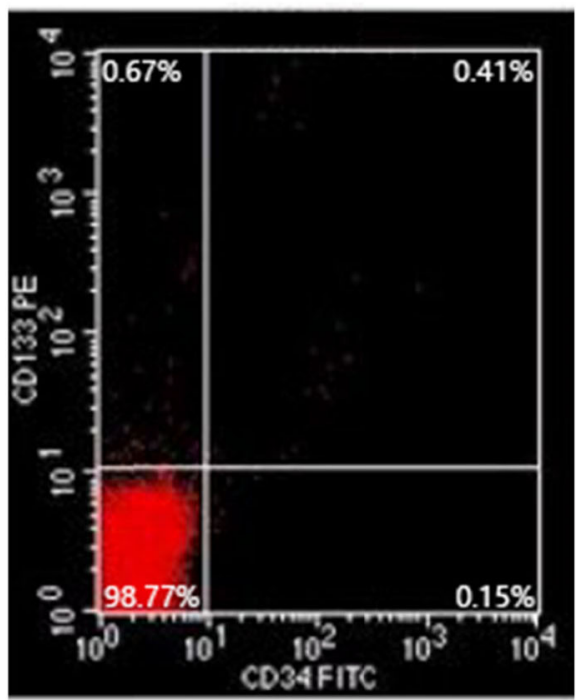

Fig. 1 Isolation and identification of human CD133 + CD34+ HPCs. Flow cytometry analysis showing the purity of CD133+ HPCS (a); and CD133HUCBCS (b) 

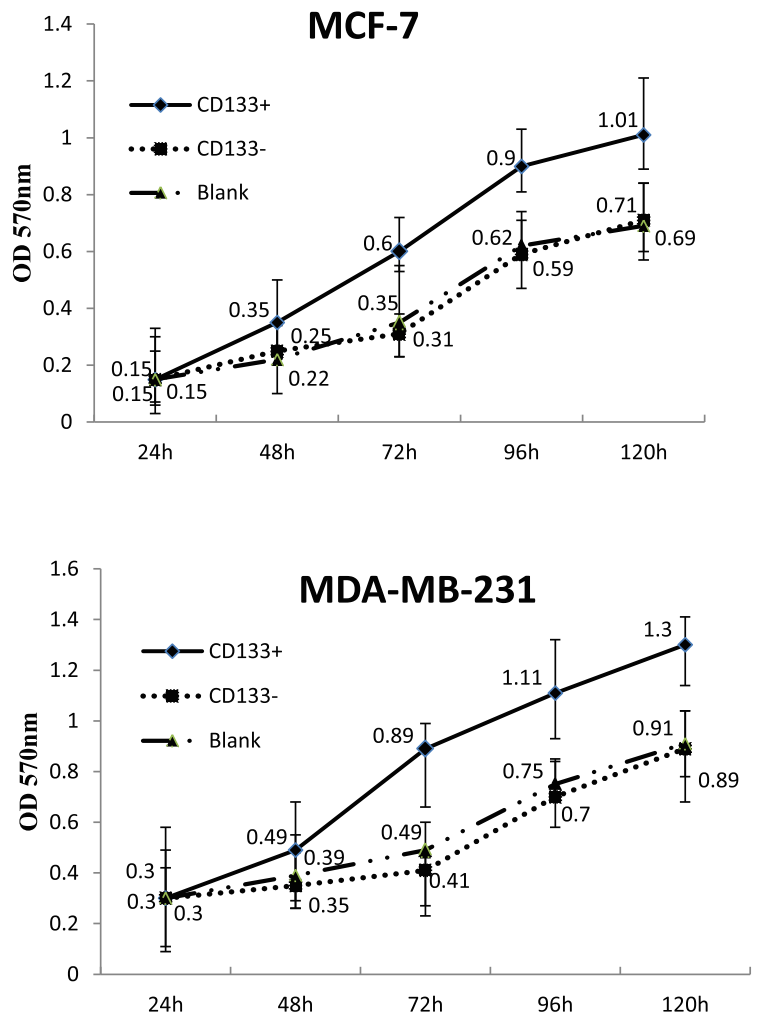

b
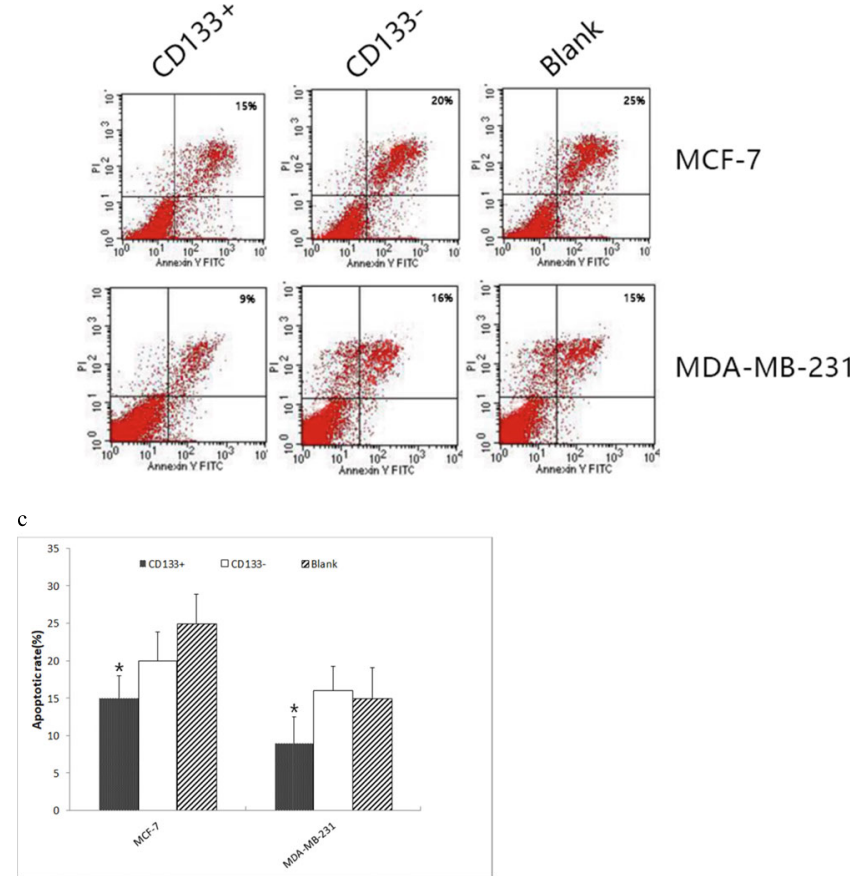

Fig. 2 CD133+ HPCs enhances breast cancer cell proliferation and reduces their apoptosis in vitro. Data show representative flow cytometry charts, or present the mean \pm SD of each group from three separate experiments. a The proliferation of cells; $\mathbf{b}$ The images of apoptotic cells; c Quantitative analysis of apoptotic cells. ${ }^{*} P<0.05$, compared with CD133- HUCBCs group 

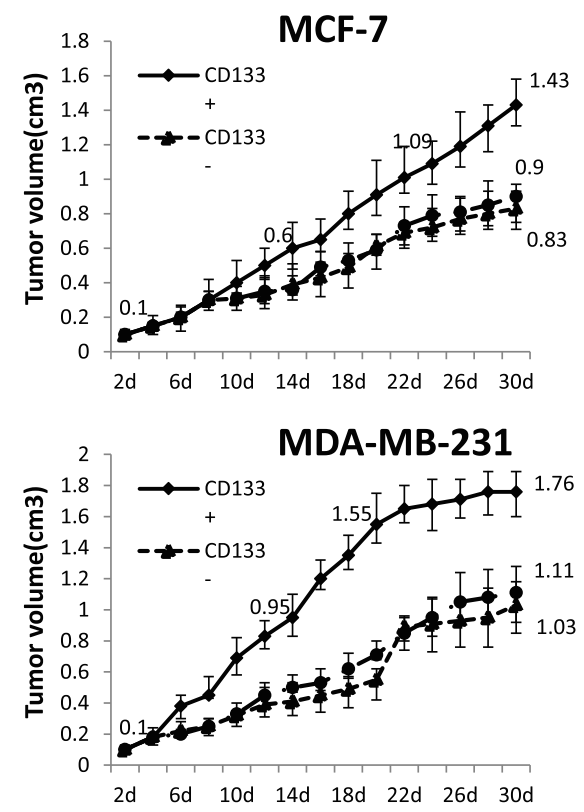

$\mathrm{b}$

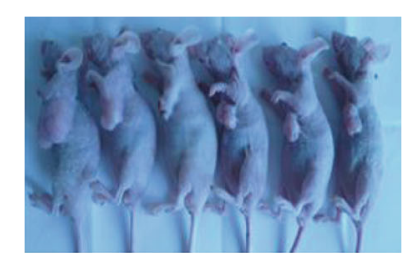

c

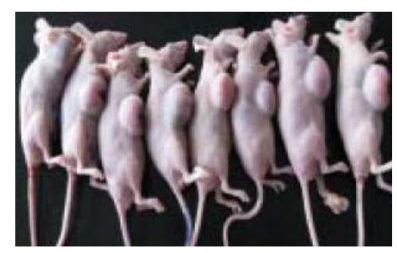

d

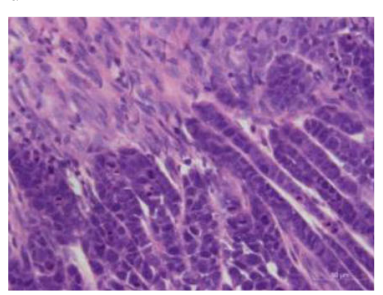

e

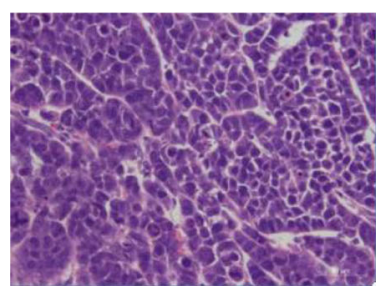

Fig. 3 CD133+ HPCs promotes breast cancer growth in vivo. Balb/c nude mice were implanted subcutaneously with MCF-7 or MDA-MB231 cells alone or together with CD133- HUCBCs or CD133+ HPCs (20:1) and the grown tumor volumes were monitored. a Data are present the mean \pm SD of each group $(n=8)$; $\mathbf{b}$ Tumor formation of MCF-7 cells in vivo; c Tumor formation of MDA-MB-231 cells in vivo; d Representative histology (H\&E) for the MCF-7 tumor tissue $(\times 400)$; e Representative histology (H\&E) for the MDA-MB-231 tumor tissue $(\times 400)$

\section{Animal experiment}

Six-week-old female BALB/c nude mice were obtained from Silaike Laboratory Animal Co., Ltd.,Shanghai, China. The protocol was authorized by the Animal Care and Use Committee of Xi'an Jiaotong University. In order to evaluate whether CD133+ HPCs affected the growth of breast cancer in vivo, a $1 \times 10^{7}$ suspension cells of MCF-7 and MDA-MB-231 breast cancer cells were taken respectively, mixed with CD133+/- cells, and inoculated to the nude mice ( $n=8$ in each group). In the experimental and negative control group, breast cancer cells and CD133+/- cells were added in a 20:1 ratio. For the negative control group, breast cancer cells and CD133- HPCs cell suspensions were added in a 20:1 ratio. For the blank control group, only breast cancer cells were inoculated. Tumor growth was monitored every 2 days for 30 days after inoculation, and the tumor volume (volume $=$ length $\times$ width $2 \times 0.5$ ) was measured. Each group of eight mice were housed in separated individual standard cleaned cages under automatically controlled air conditioning system with temperature $\left(22 \pm 2{ }^{\circ} \mathrm{C}\right.$ ), humidity (about 60\%), and lighting (12:12$\mathrm{h}$ light-dark cycle). Diet and sterilized water are provided in the experiments. At the endpoint, mice were euthanized by inhalation of $\mathrm{CO}_{2}$ followed by cervical dislocation. On the 30th day, mice were sacrificed and the tumor tissues were collected, stained with hematoxylin and eosin (H\&E) and observed under an optical microscope.

\section{Statistical analysis}

Data are expressed as mean \pm SD. We statistically analyzed the significance among groups by one way ANOVA and between groups by Student's $t$ test using the SPSS 22.0 software. A $P$-value of $<0.05$ was defined as statistical significance.

\section{Results}

Isolation and characterization of CD133+ HPCs from human umbilical cord blood

To determine the role of CD133+ HPCs in the malignancy of breast cancer cells, we isolated mononuclear cells from five UCB samples and obtained mononuclear 
cells of $(3.07 \pm 0.63) \times 10^{7} / \mathrm{ml}$. Following magnetic beadbased purification, we collected $(2.91 \pm 0.6) \times 10^{5} / \mathrm{ml}$ HPCs, accounting for $(0.95 \pm 0.011) \%$ of all mononuclear cells. Flow cytometry analysis indicated that the purity of CD133 + CD34+ HPCs was $(83 \pm 12) \%$ (Fig. 1a and b). Hence, the isolated CD133 + CD34+ HPCs had a high purity.

\section{CD133+ HPCs promote breast cancer cell proliferation} and inhibit their apoptosis in vitro

Breast cancer cells display their malignancy by rapid proliferation and potent invasion. Next, we examined the effect of CD133+ HPCs on the proliferation of breast cancer cells in vitro. We cultured MCF-7 or MDA-MB231 cells alone or together with CD133+ HPCs or CD133- HUCBCs at a cell number ratio of 20:1 for varying time periods, and we quantified breast cancer cell proliferation longitudinally by MTT assay. As shown in Fig. 2a, we observed co-culture with CD133+ HPCs significantly promoted the proliferation of MCF-7 and MDA-MB-231 cells in a time-dependent manner. While there was no significant difference in the growth rate between the cells cultured alone or co-cultured with CD133- HUCBCs in each cell line. Subsequently, we tested whether co-culture with CD133+ HPCs could modulate the spontaneous apoptosis of breast cancer cells by flow cytometry (Fig. $2 \mathrm{~b}$ and $\mathrm{c}$ ). We found that the percentages of apoptotic MCF-7 or MDA-MB-231 cells following co-culture with CD133+ HPCs $(15 \% \pm 3$, $9 \% \pm 3.8$ respectively) were significantly lower than that of culture alone or co-culture with CD133- HUCBCs $(20 \% \pm 3.5, \quad 16 \% \pm 3.2$ respectively; $P<0.05$ for all). Hence, CD133+ HPCs significantly promoted breast cancer cell proliferation and inhibited their spontaneous apoptosis in vitro.

\section{CD133+ HPCs enhance the growth of breast cancer in vivo}

We further evaluated the effect of CD133+ HPCs on the growth of breast cancer in vivo. Following inoculation of MCF-7 or MDA-MB-231 cells alone, or together with CD133+ HPCs or CD133- HUCBCs at a ratio of 20:1, we monitored the dynamic growth of implanted tumors by measuring their volumes (Fig. 3a). At day 30, coadministration of breast cancer cells with CD133+ HPCs $\left(\right.$ MCF-7 $1.43 \mathrm{~cm}^{3} \pm 0.15$, MDA-MB-231 $\left.1.76 \mathrm{~cm}^{3} \pm 0.13\right)$ significantly increased tumor volumes when compared to that of the mice with breast cancer alone and the cells mixed with CD133- HUCBCs (MCF-7 $0.83 \mathrm{~cm}^{3} \pm 0.12$, MDA-MB-231 $1.03 \mathrm{~cm}^{3} \pm 0.16 ; P<0.05$ for all). In contrast, there were no significant difference in tumor size between the mice with breast cancer alone and the cells mixed with CD133- HUCBCs. Thus, CD133+ HPCs enhanced the growth of implanted breast tumors in vivo. Histologic examination of two types of tumors are shown in Fig. 3b and c. The parenchymal cells in the cancer tissue were much more than those in the stroma, and the cancer cells were arranged in a strip like manner, in which scattered tumor cells were observed. The tumor cells were irregular with a large volume and large nucleus. The nucleoli were clear and pleomorphic. The pathological diagnosis was invasive ductal carcinoma (Fig. 3d and e).

CD133+ HPCs promote breast cancer cell invasion in vitro Breast cancer cell invasion is one of the malignant characteristics. To understand the role of CD133+ HPCs, we tested whether CD133+ HPCs could modulate breast cancer cell invasion by Transwell invasion assays. Following culture of each type of breast cancer cells alone, with CD133+ HPCs or CD133- HUCBCs

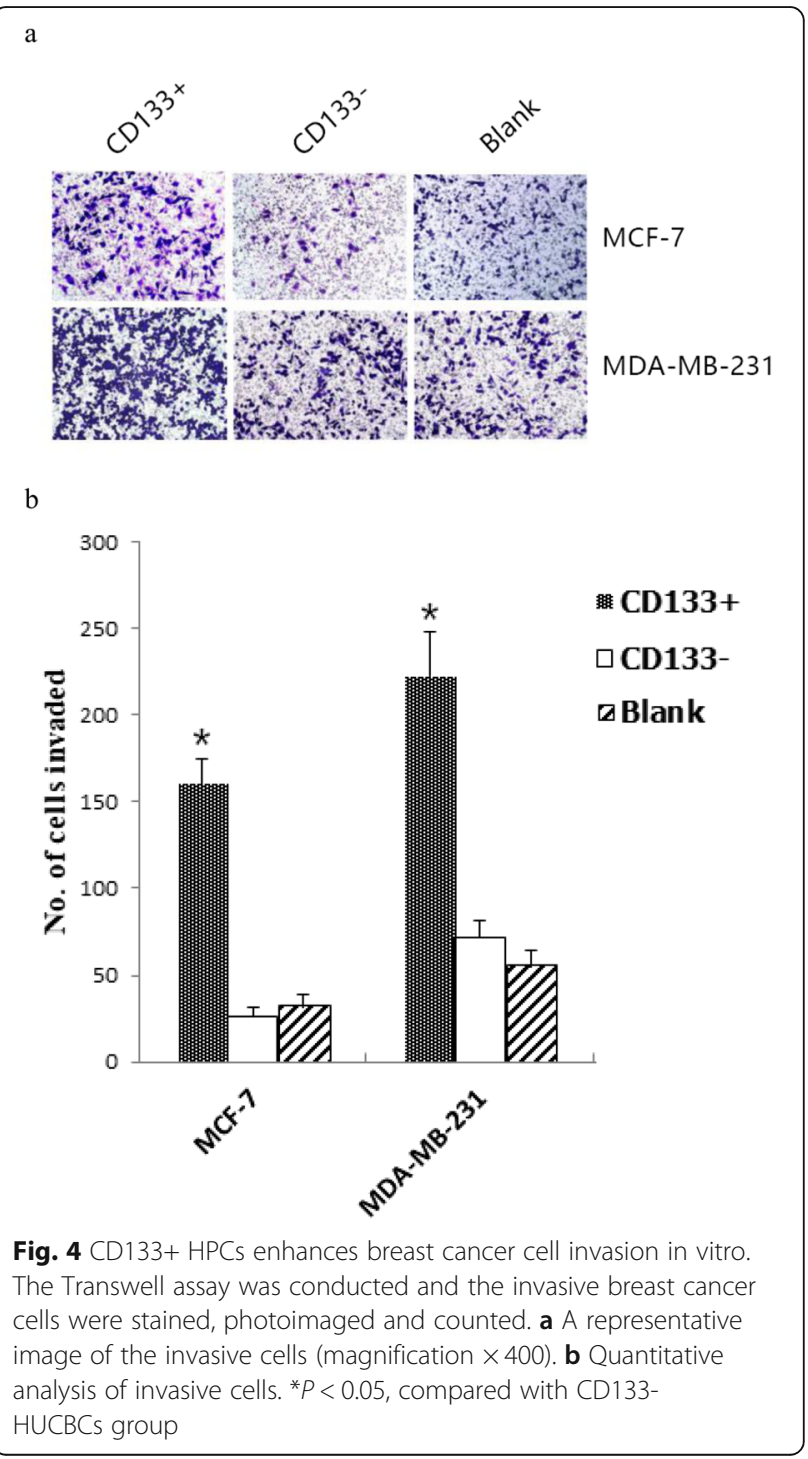


a
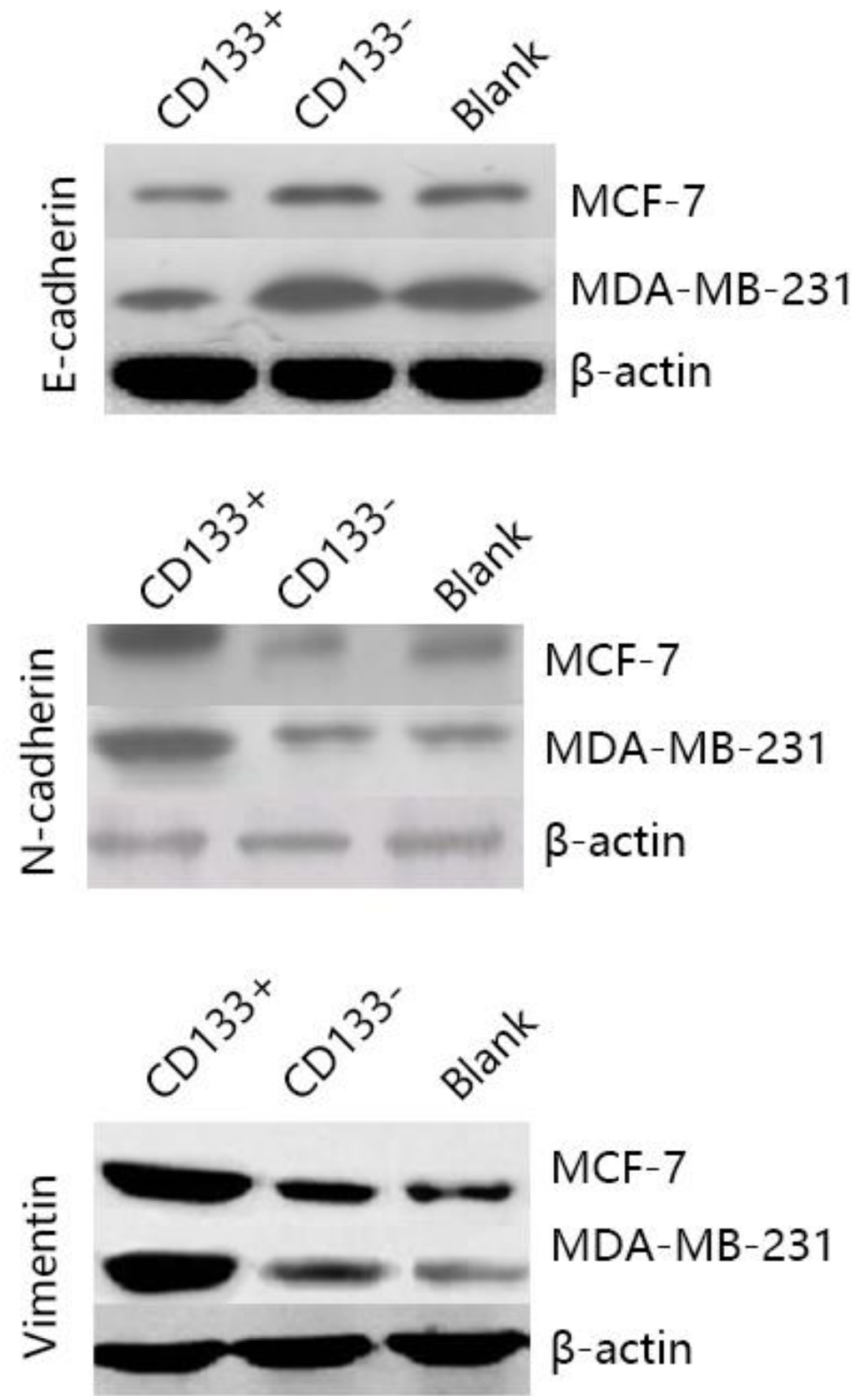

b
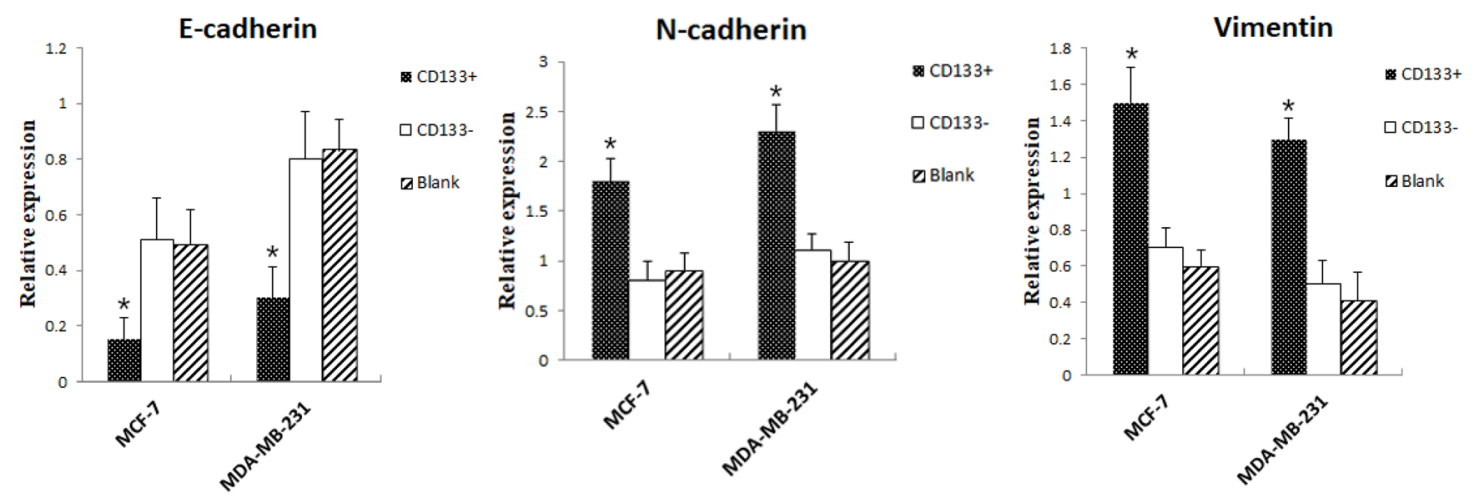

Fig. 5 (See legend on next page.) 
(See figure on previous page.)

Fig. 5 CD133+ HPCs promotes the EMT process in breast cancer cells. Breast cancer cells were culture alone or co-culture with CD133- HUCBCs or CD133+ HPCs in Transwell plates, the relative levels of E-cadherin, N-cadherin and Vimentin to the control $\beta$-actin expression in breast cancer cells were quantified by Western blot. Data are representative images or present as the mean \pm SD of each group from three separate

experiments. a Western blot analysis. $\mathbf{b}$ Quantitative analysis of each protein expression. ${ }^{*} \mathrm{P}<0.05$, compared with CD133- HUCBCs group

separately in Transwell chambers for $24 \mathrm{~h}$, we found that the numbers of invaded cells that had been cultured with CD133+ HPCs (MCF-7160 cells \pm 15 , MDA-MB231222 cells \pm 5 ) were significantly greater than that of the cells cultured alone or with CD133- HUCBCs (MCF-7 26 cells \pm 11 , MDA-MB-231 72 cells $\pm 9 ; P<0.05$ for all, Fig. 4a and b) in two different lines. We did not observe any significant difference in the numbers of invaded cells between the cell cultured alone and those with CD133- HUCBCs in our experimental system. Therefore, CD133+ HPCs enhanced breast cancer cell invasion in vitro.

\section{CD133+ HPCs enhances the process of EMT in breast cancer cells}

The EMT process is associated with invasion and metastasis of cancers. Therefore, we further explored whether CD133+ HPCs could affect the EMT process in breast cancer cells to promote invasion by quantifying the relative levels of E-cadherin, $\mathrm{N}$-cadherin and Vimentin expression using Western blot assays. The results showed that the expression of E-cadherin in MCF-7 and MDA-MB-231 breast cancer cells cocultured with CD133+ HPCs $(0.15 \pm 0.08,0.3 \pm 0.11$ respectively) was significantly lower than that cocultured with CD133- HPCs $(0.51 \pm 0.15, \quad 0.8 \pm 0.17$ respectively) and in breast cancer cells alone $(0.49 \pm 0.13$, $0.83 \pm 0.11$ respectively, $P<0.05)$. The expression of $\mathrm{N}$ cadherin in MCF-7 and MDA-MB-231 breast cancer cells co-cultured with CD133+ HPCs $(1.8 \pm 0.23,2.3 \pm$ 0.27 respectively) was significantly higher than that of co-cultured with CD133- HPCs $(0.8 \pm 0.19,1.1 \pm 0.17$ respectively) and single breast cancer cells $(0.9 \pm 0.18$, $1 \pm 0.19$ respectively; $P<0.05)$. The expression of Vimentin in MCF-7 and MDA-MB-231 breast cancer cells co-cultured with CD133+ HPCs $(1.5 \pm 0.19,1.3 \pm 0.11$ respectively) was significantly higher than that of cocultured with CD133- HPCs $(0.7 \pm 0.11,0.5 \pm 0.13$ respectively) and single breast cancer cells $(0.6 \pm 0.09,0.41 \pm 0.16$ respectively; $P<0.05$ ). We found that there were similar levels of E-cadherin, $\mathrm{N}$-cadherin and Vimentin expression in the cells cultured alone or together with CD133- HUCBCs (Fig. 5a and b). In comparison with the control, significantly down-regulated E-cadherin expression, but up-regulated N-cadherin and Vimentin expression were observed in the cells co-cultured with CD133+ HPCs $(P<0.05$ for all). Such data indicated that CD133+ HPCs promoted the EMT process in breast cancer cells.

\section{Discussion}

VEGFR1+ HPCs can promote tumor metastasis in rodent models of cancers [5]. In this study, we purified human CD133 + CD34+ HPCs from UCB.

We found that co-culture of CD133+ HPCs, but not CD133- HUCBCs, remarkably strengthened breast cancer cell proliferation and invasion, accompanied by attenuating spontaneous apoptosis in vitro and enhanced breast tumor growth in vivo. The lack of modulatory effect of CD133HUCBCs suggests that CD133 expression is an important marker for human HPCs. The increased proliferation and invasion as well as tumor growth in vivo by CD133+ HPCs indicated that CD133+ HPCs enhanced the malignancy of different types of breast cancers. Given that CD133+ HPCs enhanced breast cancer cell invasion in Transwell plates, the promoting activity of CD133+ HPCs may be mediated by secreting soluble oncogenic factors. Future studies are necessary to investigate which soluble molecules CD133+ HPCs secrete and how they enhance the malignancy of breast cancers. At the same time, the molecular and cellular changes might be induced in breast cancer cells in the presence of CD133+ HPCs have not been uncovered,the followup experimental plan of our research group is to identify possible pathways of action and study the changes of pathway which effected by the antibodies that act on CD133 + targets.

It is well known that the EMT process is associated with cancer invasion and metastasis [27]. In this study, we found that co-culture of CD133+ HPCs, but not CD133- HUCBCs significantly decreased E-cadherin, but increased $\mathrm{N}$-cadherin and Vimentin expression in breast cancer cells, indicating that CD133+ HPCs promoted the EMT process in breast cancer cells. The increased EMT process by CD133+ HPCs may also mechanistically explain how CD133+ HPCs enhance the invasion of breast cancer cells.

\section{Conclusions}

In summary, we determined that CD133+ HPCs remarkably strengthened the malignancy of breast cancer cells by enhancing their proliferation and invasion, accompanied by attenuating spontaneous apoptosis in vitro and enhancing breast tumor growth in vivo. Furthermore, CD133+ HPCs increased the 
EMT process in breast cancer cells. Given that CD133+ HPCs can circulate in peripheral blood, such type of cells may contribute to the pathological process of breast cancer. Therefore, CD133+ HPCs may be new targets for therapies against breast cancer metastasis and invasion.

\section{Supplementary Information}

The online version contains supplementary material available at https://doi. org/10.1186/s12885-020-07633-3.

Additional file 1 : Figure 1. a. The relative levels of E-cadherin to the control $\beta$-actin expression in breast cancer cells were quantified by Western blot. $\mathrm{b}$. The relative levels of $\mathrm{N}$-cadherin to the control $\beta$-actin expression in breast cancer cells were quantified by Western blot. c. The relative levels of Vimentin to the control $\beta$-actin expression in breast cancer cells were quantified by Western blot.

\section{Abbreviations}

HPCs: Hematopoietic progenitor cells; UCB: Umbilical cord blood; EMT: Epithelial mesenchymal transition; HUCBCs: Human umbilical cord blood cells; MTT: 3-(4,5-dimethylthiazol-2-yl)-2,5-diphenyltetrazolium bromide

\section{Acknowledgements}

Not applicable

\section{Authors' contributions}

Conceived and designed the experiments: XH Z, QL Z. Performed the experiments: ZZ, RW, JZ, SH. Analyzed the data: LQ S, PP H. Contributed reagents/materials/analysis tools and expertise: $\mathrm{YH} \mathrm{L}$. Wrote the manuscript: ZZ. All authors approved the submitted version.

\section{Funding}

This study was supported by a grant from the National Natural Science Foundation of China (no. 81072181). The funder had no work in study design, data collection and analysis, animal experiments, interpretation, decision to publish, or preparation of this manuscript.

\section{Availability of data and materials}

The data to support the findings of this study are available upon reasonable request from the corresponding author, but restrictions apply to the availability of these data, which were used under license for the current study, and so are not publicly available.

\section{Ethics approval and consent to participate}

Ethical approval was obtained for collection of human UCB samples from First Affiliated Hospital, College of Medicine at Xi'an Jiaotong University (2017-041). Written informed consent was signed the parents of individual newborns. Animal experiments were approved prior to the beginning of the study and were conducted by the Animal Care and Use Committee of Xi'an Jiaotong University (license number: SCXK 2017-003).

\section{Consent for publication}

Not applicable.

\section{Competing interests}

The authors declare that they have no competing interests.

\section{Author details}

'Department of Traditional Chinese Medicine, the First Affiliated Hospital of Medical School of Xi'an Jiaotong University, Xi'an, Shaanxi 710061, People's Republic of China. 'Department of Medical Oncology, the First Affiliated Hospital of Medical School of Xi'an Jiaotong University, Xi'an, Shaanxi 710061, People's Republic of China.
Received: 27 April 2020 Accepted: 12 November 2020

Published online: 26 November 2020

\section{References}

1. Xinlu W, Minying Z, Fei F, Chunyuan L, Jiaxing D. EMT-related protein expression in polyploid giant cancer cells and their daughter cells with different passages after triptolide treatment. Med Oncol. 2019;36:102-20..

2. Styliani M, Emilia W, Mustafa M, Mayur VJ, Man KC. The effect of $2 D$ and 3D cell cultures on treatment response, EMT profile and stem cell features in head and neck cancer. Cancer Cell Int. 2019;19:1502-19.

3. Savas DS, Alexandar T, Simone EM. Role of the tumor microenvironment in breast cancer. Pathobiology. 2015;82:142-52.

4. Jean A, Mario AS, David N, Chun GP, Alexandra A, Morgan EP, Priya U, et al. Neutrophil extracellular traps produced during inflammation awaken dormant cancer cells in mice. Science. 2018:361:4227-35.

5. Kaplan RN, Psaila B, Lyden D. Bone marrow cells in the 'pre-metastatic niche': within bone and beyond. Cancer Metast Rev. 2006;25:521-9.

6. Herr F, Horndasch M, Howe D, Baal N, Goyal P. Human placenta-derived Wnt-5a induces the expression of ICAM-1 and VCAM-1 in CD133(+)CD34(+ )-hematopoietic progenitor cells. Reprod Biol. 2014;14:262-75.

7. Gullo F, van der Garde M, Russo G, Pennisi M, Motta S. Computational modeling of the expansion of human cord blood CD133(+) hematopoietic stem/progenitor cells with different cytokine combinations. Bioinformatics. 2015:31:2514-22

8. Bhatia S, Reister S, Mahotka C, Meisel R, Borkhardt A. Control of AC133/ CD133 and impact on human hematopoietic progenitor cells through nucleolin. Leukemia. 2015;29:2208-20.

9. Maryam H, Amir A, Behnaz B, Mahboubeh K, Samad N. MicroRNAs as Markers for Neurally Committed CD133+/CD34+ Stem Cells Derived from Human Umbilical Cord Blood. Biochem Genet. 2013;51:175-88.

10. Reichert D, Scheinpflug J, Karbanova J, Freund D, Bornhauser M. Tunneling nanotubes mediate the transfer of stem cell marker CD133 between hematopoietic progenitor cells. Exp Hematol. 2016;11:1092-112.

11. Cimato TR, Conway A, Nichols J, Wallace PK. CD133 expression in circulating hematopoietic progenitor cells. Cytom Part B Clin Cy. 2019;96:39-45.

12. Aghajani M, Mansoori B, Mohammadi A, Asadzadeh Z, Baradaran B. New emerging roles of CD133 in cancer stem cell: Signaling pathway and miRNA regulation. J Cell Physiol. 2019;234:21642-61.

13. Zyuzkov GN, Zhdanov W, Udut EV, Miroshnichenko LA, Polyakova TY. Peculiarities of Intracellular Signal Transduction in the Regulation of Functions of Mesenchymal, Neural, and Hematopoietic Progenitor Cells. B Exp Biol Med. 2019;167:201-6.

14. Nicholas Z. Immunity of embryonic stem cell-derived hematopoietic progenitor cells. Semin Immunopathol. 2011;33:613-7.

15. Quanfu M, Sharon C, Sailaja G, James FP, Monique E, De P. Ex vivo expanded human cord blood-derived hematopoietic progenitor cells induce lung growth and alveolarization in injured newborn lungs. Resp Res. 2013:14:1201-19.

16. Kiho S, Sunhyun K, Byungsoo Y, Hansoo K. Globular adiponectin induces leukocytosis and mobilizes hematopoietic progenitor cells in mice. Tissue Eng Regen Med. 2015;12:449-56.

17. Andrea Z, Tuckett RH, Thornton RJ, Oreilly RM, Brink JL, Zakrzewski. Intrathymic injection of hematopoietic progenitor cells establishes functional $T$ cell development in a mouse model of severe combined immunodeficiency. J Hematol Oncol. 2017;10:109-17.

18. Burgstaler EA, Winters JL. Hematopoietic Progenitor Cells, Apheresis and Therapeutic Cells, T-Cells Collection: Instrumentation, Operating Parameters, and Troubleshooting. Hematopoietic Cell T. 2019;10:81-100.

19. Duong HT, Erzurum SC, Kewal A. Pro-angiogenic hematopoietic progenitor cells and endothelial colony-forming cells in pathological angiogenesis of bronchial and pulmonary circulation. Angiogenesis. 2011;14:411-22.

20. Martin SH, Robert D, Babette A, Philipp L, Antonia B. In vitro effects of perifosine, bortezomib and lenalidomide against hematopoietic progenitor cells from healthy donors. Invest New Drug. 2012;30:1396-403.

21. Zhang C, Zhou C, Wu XJ, Yang M, Yang ZH, Xiong HZ, et al. Human CD133 positive hematopoietic progenitor cells initiate growth and metastasis of colorectal cancer cells. Carcinogenesis. 2014:12:2771-7.

22. Kathrin T, Bauermeister S, Stolting PM, Kaczmarek RN, Thomas W, Stefan OP. Hematopoietic Progenitor Cells Residing in Muscle Engraft into Bone Marrow following Transplantation. Int J Hematol. 2004;79:488-94. 
23. Karami K, Rahimi M, Zakariazadeh M, Buyukgungor O, Amirghofran Z. New phosphorus ylide palladacyclic: Synthesis, characterization, X-Ray crystal structure, biomolecular interaction studies, molecular docking and in vitro cytotoxicity evaluations. J Organomet Chem. 2018:878:60-76.

24. Li S, Fang XD, Wang XY, Fei BY. Fos-like antigen 2 (FOSL2) promotes metastasis in colon cancer. Exp Cell Res. 2018;373:57-61.

25. Wang HF, Wu JH, Gai JW, Yang SQ, Ma QT, Ma HS, et al. MAN1B1 is associated with poor prognosis and modulates proliferation and apoptosis in bladder cancer. Gene. 2018;679:314-9.

26. Wang X, Gao JL, Zhao MM, Zhu HX, Tian YX, Li R, et al. Therapeutic effects of conditioned medium from bone marrow-derived mesenchymal stem cells on epithelial-mesenchymal transition in A549 cells. Int J Mol Med. 2018:41:659-68.

27. Jihong L, Chunxiao L, Liyan Z, Kai L, Xianli J. Association of tumourassociated macrophages with cancer cell EMT, invasion, and metastasis of Kazakh oesophageal squamous cell cancer. Diagn Pathol. 2019;14:891-905.

\section{Publisher's Note}

Springer Nature remains neutral with regard to jurisdictional claims in published maps and institutional affiliations.

Ready to submit your research? Choose BMC and benefit from:

- fast, convenient online submission

- thorough peer review by experienced researchers in your field

- rapid publication on acceptance

- support for research data, including large and complex data types

- gold Open Access which fosters wider collaboration and increased citations

- maximum visibility for your research: over $100 \mathrm{M}$ website views per year

At $\mathrm{BMC}$, research is always in progress.

Learn more biomedcentral.com/submissions 